Research Article

\title{
Experimental Study on Freeze-Thaw Cycle Duration of Saturated Tuff
}

\author{
Man Huang $\mathbb{D}^{1,2}$ Bin Tang, ${ }^{1,2}$ Jianliang Jiang, ${ }^{3}$ Renqiu Guan, ${ }^{3}$ and Huajun Wang $^{3}$ \\ ${ }^{1}$ Department of Civil Engineering, Shaoxing University, Shaoxing 312000, Zhejiang, China \\ ${ }^{2}$ Zhejiang Collaborative Innovation Center for Prevention and Control of Mountain Geologic Hazards, Shaoxing, \\ Zhejiang, China \\ ${ }^{3}$ Zhejiang Engineering Survey Institute, Ningbo 315012, China
}

Correspondence should be addressed to Man Huang; hmcadx@126.com

Received 2 June 2020; Revised 8 July 2020; Accepted 9 July 2020; Published 24 July 2020

Academic Editor: Hang Lin

Copyright (c) 2020 Man Huang et al. This is an open access article distributed under the Creative Commons Attribution License, which permits unrestricted use, distribution, and reproduction in any medium, provided the original work is properly cited.

\begin{abstract}
The freeze-thaw duration is one of the important factors affecting the change of rock properties. However, this factor has not formed a unified standard in the freeze-thaw cycle test. This study uses saturated tuff samples taken from eastern Zhejiang, China, as research objects to explore the change law of the time required for the rock to reach a full freeze-thaw cycle. Measured results show that the total duration of the freeze-thaw cycle presents an increasing power function with the increase in the number of freeze-thaw cycles. The freezing process is divided into three phases: initial freezing, water-ice phase transition, and deep freezing. The melting process is also divided into three phases: initial melting, ice-water phase transition, and deep melting. The time required for the ice-water phase change stage of the melting process does not change with the increase in the number of freezethaw cycles, while the other stages increase as a power function. The proportion of duration of each stage in the freezing process does not change with the increase in the number of cycles. By contrast, the duration proportion of the initial melting phase in the melting process decreases, and the deep melting phase increases. Experimental results of the freeze-thaw cycles of tuff demonstrate that the freeze-thaw duration of the freeze-thaw cycles within 40 times can be set to $9 \mathrm{~h}$. The freezing and melting processes are 6 and $3 \mathrm{~h}$, respectively.
\end{abstract}

\section{Introduction}

The physical and mechanical properties of rocks have always been the focus of scholars' research, and a lot of in-depth studies have been carried out [1-5]. As the research progressed, people pay increasing attention to the freeze-thaw cycle of rocks with the development of resources. Several scholars have found many factors, such as cycle time, cycle temperature, and number of cycles, which affect the freezethaw cycle test. The determination of the freeze-thaw cycle time is a prerequisite for the freeze-thaw cycle test. Therefore, the regularity of the freeze-thaw cycles of rocks must be studied to improve the result accuracy.

Many scholars have carried out several studies on the freeze-thaw cycles of rocks and summarized the types of cycle duration adopted by various freeze-thaw cycle test institutes at present. These types of cycle can be divided into the following four categories: (1) the cycle test temperature ranges from $-20^{\circ} \mathrm{C}$ to $32^{\circ} \mathrm{C}$. The cycle time of the freezing and melting processes is $12 \mathrm{~h}$. Jamshidi et al. used a salt solution instead of water on the tuff for the freeze-thaw cycle damage test to study its effect during the freeze-thaw cycle test [6]. Al-Omari et al. studied the influence of limestone degradation at $-18^{\circ} \mathrm{C}$ to $+32^{\circ} \mathrm{C}$ [7]. Liu et al. used a freezethaw cycle test at a temperature range of $+5( \pm 1)^{\circ} \mathrm{C}$ to -20 $( \pm 1)^{\circ} \mathrm{C}$ to study the damage expansion law of red sandstone and shale [8]. Yu et al. studied the effects of freeze-thaw cycles on the mechanical properties and permeability of red sandstone under triaxial compression [9]. (2) The same $4 \mathrm{~h}$ freezing and $4 \mathrm{~h}$ melting process cycle times are used at different freeze-thaw cycle test temperatures. Li et al., Wang et al., and Park reported that the types of rocks have different 
freeze-thaw cycle tests with varying temperature ranges and the same freeze-thaw cycle duration [10-12]. Li et al. carried out uniaxial compression tests on granite under different freeze-thaw cycles and obtained the intensity change law [13]. (3) The freezing and thawing cycle temperature range is $-20^{\circ} \mathrm{C}$ to $20^{\circ} \mathrm{C}$, and the freezing and melting times are 15 and $9 \mathrm{~h}$, respectively. Momeni et al. performed freeze-thaw cycle tests on sandstone at a temperature range of $-20^{\circ} \mathrm{C}$ to $20^{\circ}$ [14]. Khanlari et al. measured the wave velocity, porosity, and uniaxial compressive strength of five different sandstones [15]. (4) Other freeze-thaw cycle duration ranges. Yavuz et al. and Bayram used a freeze-thaw cycle test with a freeze-thaw cycle of $4 \mathrm{~h}$ to analyze the degradation characteristics of limestone, tuff, and marble and examine the mechanical strength loss [16, 17]. Matsuoka used a $12 \mathrm{~h}$ freeze-thaw cycle test on a variety of rocks to study their degradation mechanisms [18]. Demirdag studied the effects of freeze-thaw cycles on the physical and mechanical properties of travertine and saturated travertine and compared their mechanical parameters [19]. Mokhfi et al. used a $24 \mathrm{~h}$ freeze-thaw cycle to assess the risk of limestone deterioration [20]. Huseyin performed a freeze-thaw cycle test on andesite for $6 \mathrm{~h}$ and the melting process for $18 \mathrm{~h}$ [21]. Then, the author measured the changes in the physical and mechanical characteristics of andesite. Gao et al. adopted the $8 \mathrm{~h}$ freezing and $8 \mathrm{~h}$ melting processes. Red sandstone is subjected to freeze-thaw cycles under different chemical solutions to study the change characteristics of red sandstone damage under the coupling of chemical action and freeze-thaw cycle [22]. The different test specifications of various countries also provide the corresponding freezethaw cycle temperature range and cycle time. The Chinese specifications stipulate that the freeze-thaw cycle temperature range is $-20^{\circ} \mathrm{C}( \pm 2)$ to $20^{\circ} \mathrm{C}( \pm 2)$, and the freezing process is $4 \mathrm{~h}$. The melting process is $4 \mathrm{~h}[23,24]$. The international norms stipulate that the freeze-thaw cycle temperature range is $-20^{\circ} \mathrm{C}( \pm 2)$ to $20^{\circ} \mathrm{C}( \pm 2)$, and the freezing and melting processes are 15 and $9 \mathrm{~h}$, respectively [25].

In summary, most scholars paid attention to the analysis of the physical and mechanical characteristics when performing the freeze-thaw cycle test. The freeze-thaw cycle duration is taken as the experimental norm value. However, the freeze-thaw cycle duration and temperature are not used. The relationship between changes is carefully considered. However, the duration and temperature range are factors that must be considered in the freeze-thaw cycle test. On this basis, this work measures the time required to reach a full freeze-thaw cycle for the tuff. The freeze-thaw cycle is divided into freezing and thawing processes. The time variation rules of each process are analyzed to provide the corresponding basis for the overall time of the freeze-thaw cycle test of tuff and the time required for different processes.

\section{Materials and Methods}

2.1. Sample Preparation. The original samples are tuffs from Zhejiang Province, China. The obtained samples are processed and made into a sample of $\Phi 50 \mathrm{~mm} \times 100 \mathrm{~mm}$. These samples meet the requirements of the International Society of Rock Mechanics for the aspect ratio of 2.0 to 2.5. The accuracy of the test piece production meets the requirements for the deviation of the unevenness of the two end surfaces within $\pm 0.05 \mathrm{~mm}$. The end face is perpendicular to the axial surface of the test piece, and the angular deviation is not greater than $\pm 0.25^{\circ}$. The adjacent sides of the cylinder are perpendicular to each other, and the deviation is less than $\pm 0.25^{\circ}$. After the preparation of the samples is completed, the samples with obvious defects are first removed. Then, the longitudinal wave velocity $\left(V_{\mathrm{P}}\right)$ of each sample is measured with a sonic tester. The samples with similar wave speeds are grouped together, as shown in Figure 1. The samples of the same group are drilled at the center position. The diameter and depth of the holes are severally 6 and $25 \mathrm{~mm}$. The measured initial physical parameters of the samples are shown in Table 1.

2.2. Experimental Procedure. The processed sample is placed in a drying box at $107^{\circ} \mathrm{C}\left( \pm 1^{\circ} \mathrm{C}\right)$ and dried until the quality did not change. Then, the sample is taken out, submerged into warm water at $20^{\circ} \mathrm{C}$, and subjected to natural saturated water treatment for $48 \mathrm{~h}$. The temperature sensor probe is then placed in the sample borehole and externally connected to the temperature collector. Finally, impervious plasticine is used to seal the hole surface. The sealed sample is wrapped in plastic and quickly placed in a $-20^{\circ} \mathrm{C}$ low-temperature test chamber. The change in probe temperature over time is measured and recorded in real time until the probe temperature reached $-20^{\circ} \mathrm{C}\left( \pm 1^{\circ} \mathrm{C}\right)$. The frozen sample is taken out and quickly placed in a $20^{\circ} \mathrm{C}\left( \pm 1^{\circ} \mathrm{C}\right)$ incubator. The change in temperature of the probe over time is measured and recorded. The melting process is completed when the temperature of the probe reached $20^{\circ} \mathrm{C}\left( \pm 1^{\circ} \mathrm{C}\right)$, and it is recorded as a freeze-thaw cycle. The freeze-thaw cycle process is repeated until each sample reached 40 freeze-thaw cycles, and the test is ended. During the test, the law of the time required for the freezing and thawing processes and the complete freeze-thaw cycle of the rock is obtained. The specific freeze-thaw cycle time value of the rock test is also obtained.

\section{Results}

3.1. Freeze-Thaw Cycle Process Analysis. The freezing process is similar to the thawing process for all freeze-thaw cycles. This study takes any group for analysis (Figure 2). The freezing and thawing processes in the freeze-thaw cycle can be divided into three stages according to different temperatures: initial freezing and melting, phase transition, and deep freezing and melting.

In the sample freezing process, the first stage is the precooling stage, which is the decrease from the $20^{\circ} \mathrm{C}$ to the temperature of the water-ice phase transition stage (approximately $0^{\circ} \mathrm{C}$ ). The temperature of the rock sample at this stage is greatly different from the external temperature. The large convective heat transfer coefficient in the stage leads to rapid changes in the internal temperature of the rock sample. 


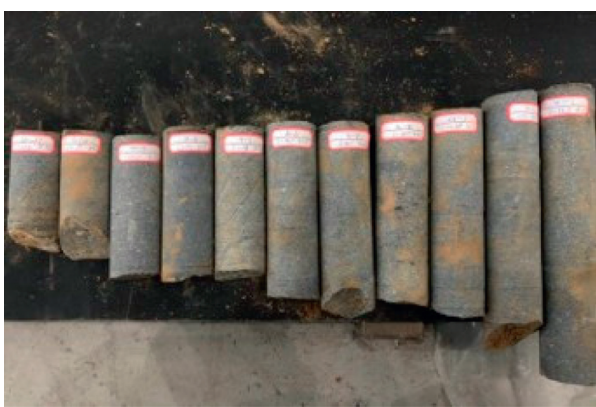

(a)

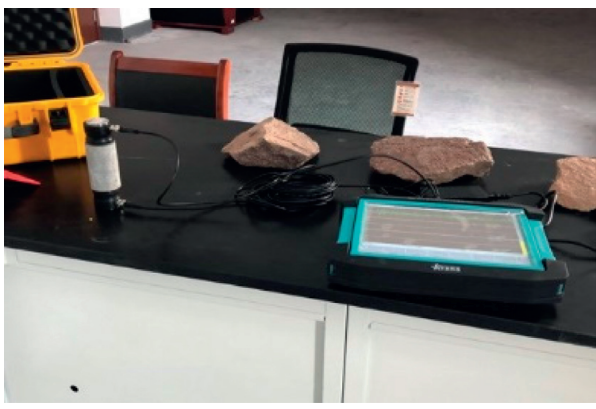

(c)

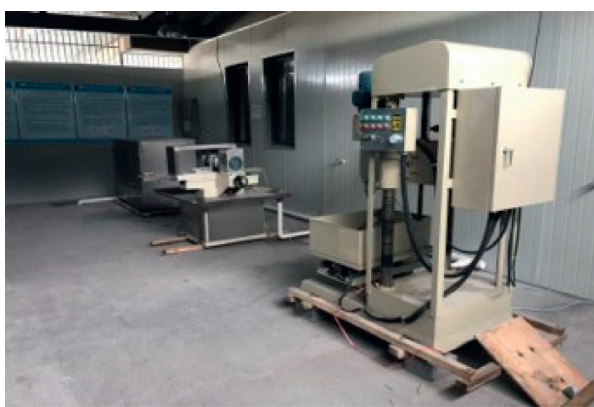

(b)

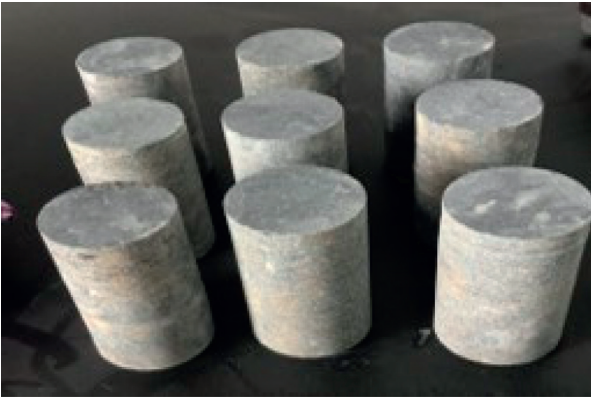

(d)

FIGURE 1: Sample preparation chart. (a) Initial sample; (b) rock sample cutting and polishing machine; (c) wave velocity measurement; (d) standard sample.

TABLE 1: Initial physical parameters of tuff.

\begin{tabular}{lccc}
\hline Lithology & Dry density $\left(\mathrm{g} \cdot \mathrm{cm}^{-3}\right)$ & Natural moisture content $(\%)$ & Initial wave velocity $(\mathrm{km} \cdot \mathrm{s})$ \\
\hline Tuff & 3.04 & 0.28 & 3.125 \\
\hline
\end{tabular}

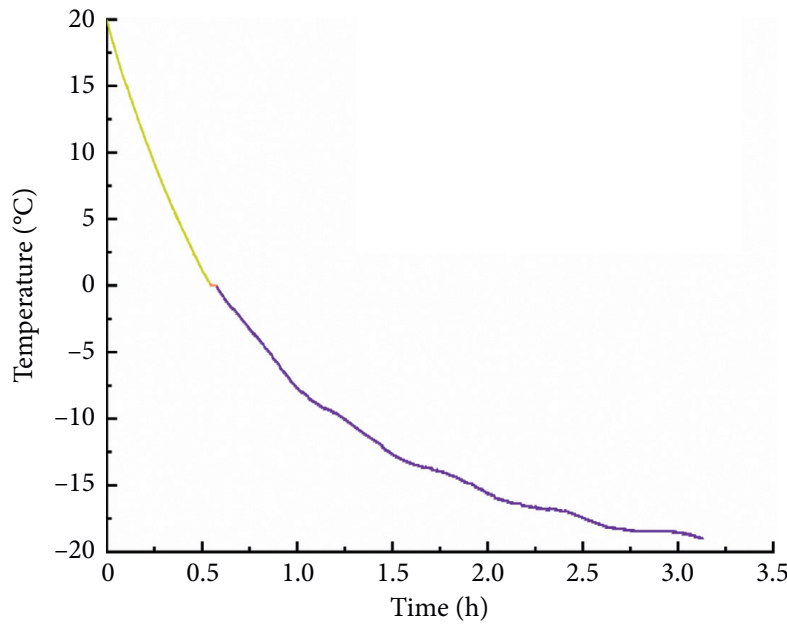

- Initial freezing stage

- Phase transition stage

- Deep freezing stage

(a)

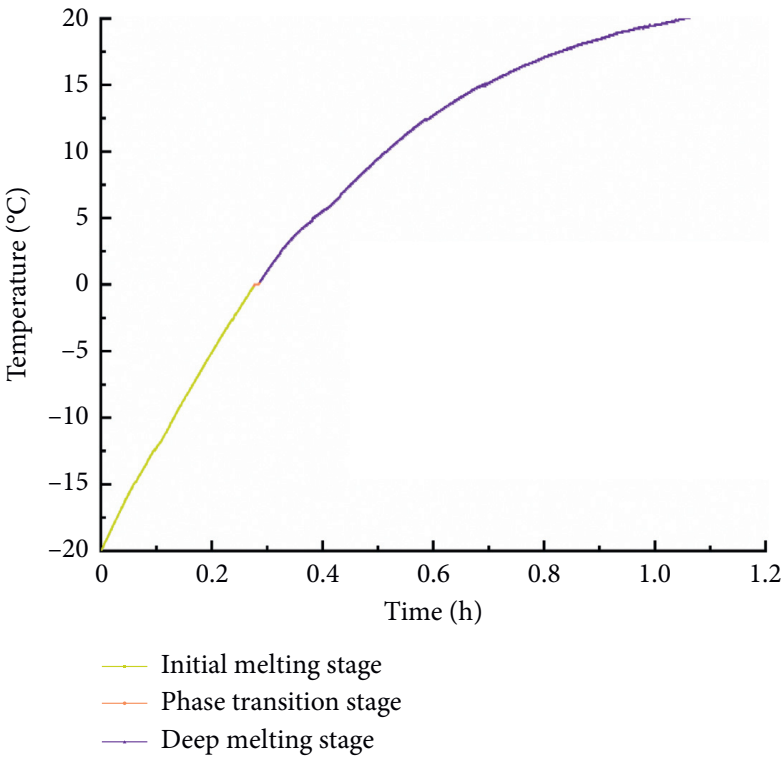

(b)

FIgURE 2: Time diagram of the rock sample reaching the specified temperature for the fifth freeze-thaw cycle. (a) Freezing process; (b) melting process. 
The temperature does not significantly change until the pore water begins to undergo water-ice phase transformation. The second stage is the water-ice phase transition phase. In this phase, the pore water that can flow in the sample is gradually converted from water and releases a substantial amount of latent heat. The tuff used in this test is a hard rock, and its water absorption is low. In this test, the duration of the water-ice phase transition period is short. Nevertheless, the overall duration curve first increases and then gradually stabilizes. The change indirectly reflects the increase in the internal porosity of the rock, thereby leading to a sufficient phase transition process. Accordingly, the time gradually increases, and it eventually shows a trend of stabilization because of the constant water content. The third stage is the cryogenic phase. The pore water gradually freezes during the transition phase, but it is not completely frozen. Accordingly, the pore water is still undergoing the water-ice phase transition process during the cryogenic phase. The difference between the internal and external temperatures is relatively small. The heat is low; thus, the temperature change rate at this stage gradually decreases. The final internal temperature reaches $-20^{\circ} \mathrm{C}$.

In the melting process of the sample, the first stage is the preheating stage. The temperature range of this stage is from $-20^{\circ} \mathrm{C}$ to the freezing temperature of the porous ice inside the rock sample. The temperature of the rock sample and the ambient temperature in this stage are quite different. The convective heat transfer coefficient is relatively large; hence, the temperature change rate is fast. Nevertheless, an icewater phase change occurs in the pore ice with time, thereby absorbing a large amount of heat and decreasing the overall temperature change rate. The second stage is the ice-water phase transition phase. The duration of this phase gradually increases with the number of cycles. However, the overall time of this stage is less than that of the water-ice phase transition phase during freezing. This phenomenon is because of the thermal conductivity of ice that is four times that of water. Hence, the time in this stage is shorter than that of the water-ice phase transition phase in the frozen state. The third stage is the deep heat stage, which is from the end of the ice-water phase transition stage to the specified temperature. The principle of the cryogenic phase of the freezing process is similar to this phase.

3.2. Analysis of Freeze-Thaw Cycle Test Results. This study measures the time law of tuff reaching full freezing and complete melting in different numbers of freeze-thaw cycles $n$. The corresponding diagram is shown in Figure 3. This task is conducted because the thermal conductivity of water is four times that of ice, and water needs to change temperature. The amount of heat is two times that of ice. Accordingly, the time required for the freezing process during the freeze-thaw cycle is much greater than that for the melting process. The deep freezing stage in the freezing process is the main time proportion to the freezing stage. The time of the deep melting stage in the melting process is also larger than that of the initial melting stage. However, such time is much smaller than the deep freezing stage time in the total freezing process. The temperature change rate of the initial freezing and thawing stages with the increasing times is less obvious than that of the deep freezing and thawing stages. The time required for the freeze-thaw cycle gradually increased with the increase in the number of freeze-thaw cycles. The test measured that the time required for the freeze-thaw cycle of the tuff increased from the first $4 \mathrm{~h}$ to the last $8 \mathrm{~h}$ before it stabilized. The change law is roughly the same. The experimental results in Figure 4 demonstrate that the time required for the complete freeze-thaw cycle to increase with the number of freezethaw cycles meets the power function law of $y=a x^{b}+c$. The formula of the time required for the complete freezethaw cycle of the tuff to increase with the number of times is obtained:

$$
T_{t}=6.93 n^{0.14}-4.5 \text {, }
$$

where $n$ is the number of freeze-thaw cycles and $T_{t}$ is the time required for complete freeze-thaw cycles of tuff under $n$ times.

During freezing, the time required for the process gradually increases with the increase in the number of freeze-thaw cycles. Furthermore, the change rate $\varepsilon$ that can show variation of the freeze-thaw cycle with the number of cycles is calculated by the following formula:

$$
\varepsilon=\frac{\left|F_{n+5}-F_{n}\right|}{F_{n}},
$$

where $F_{n}$ and $F_{n+5}$ are the duration of the freezing process when the number of freeze-thaw cycles is $n$ and $n+5$, respectively.

It can be obtained from Figure 5 that the duration of the freeze-thaw cycle varied greatly before the 10 freeze-thaw cycles. However, with the increase in the number of times, the change rate stabilized below $15 \%$, and the change rate is basically similar. The proportion of this process in the total duration increased from $75 \%$ to $83 \%$ at the beginning. This finding indicates that the proportion of time required for the freezing process has gradually increased with the increase in the number of freeze-thaw cycles. Meanwhile, the proportion of time for the melting process has gradually increased. This study illustrates the change of the time required for the freezing process to achieve complete freezing as a function of the number of cycles (Figure 6). The scatter plot shows that the time required for the freezing process to increase with the number of freeze-thaw cycles meets the power function law of $y=a x^{b}+c$. The time required for the freezing process of the tuff to increase with the number of times is given by using fitting:

$$
T_{f}=2.09 n^{0.29}-0.14
$$

where $n$ is the number of freeze-thaw cycles and $T_{f}$ is the time required for the tuff freezing process under $n$ times.

The thawing process is similar to the freezing process. The time required for the process gradually increases with the increase in the number of freeze-thaw cycles. Furthermore, formula (4) is adopted to quantify the change rate of its duration: 


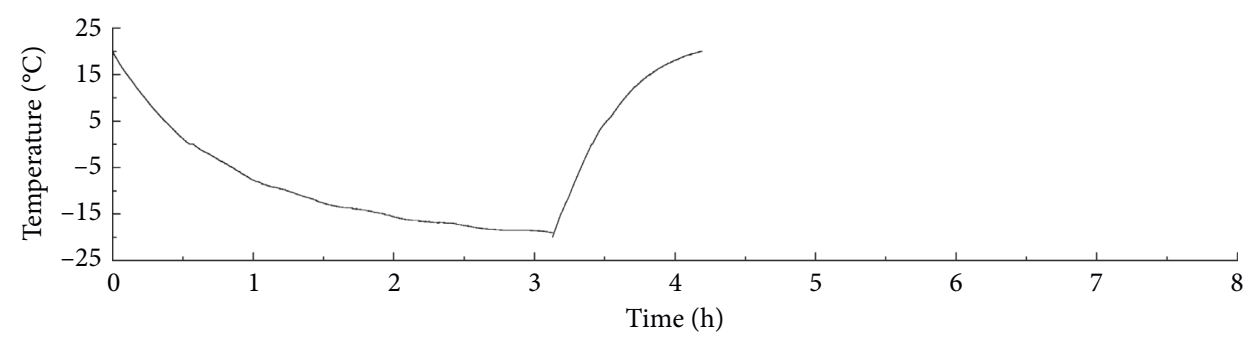

(a)

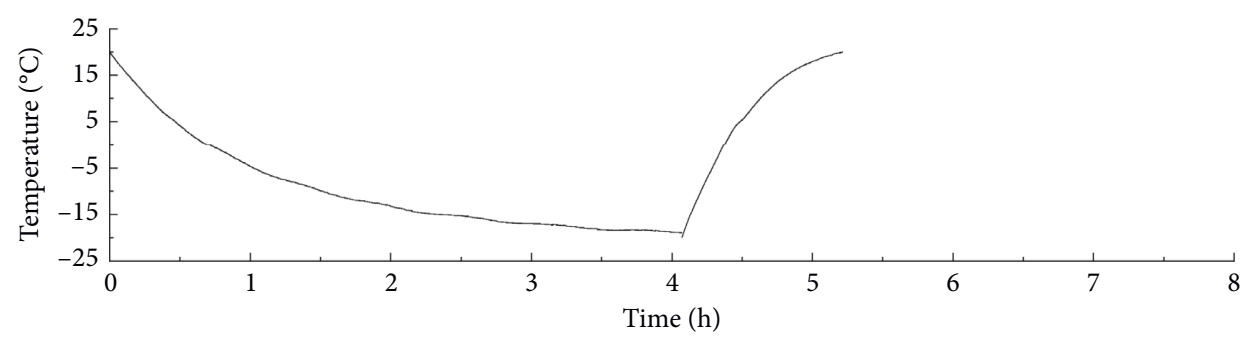

(b)

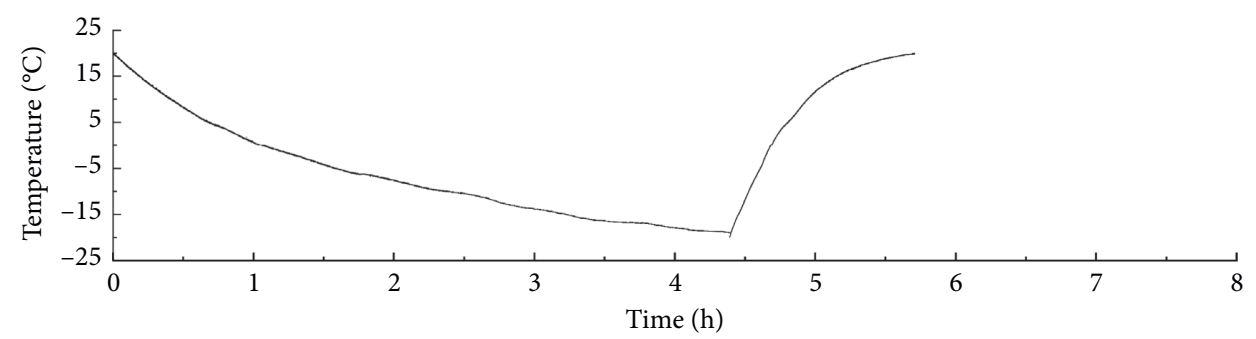

(c)

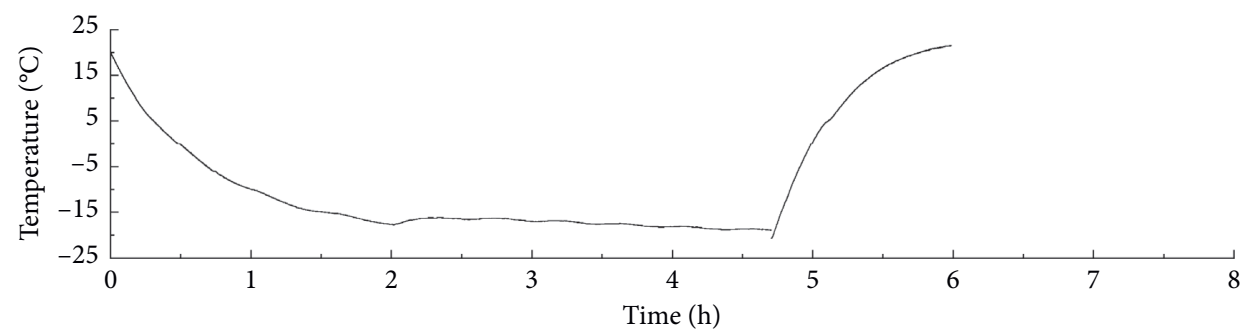

(d)

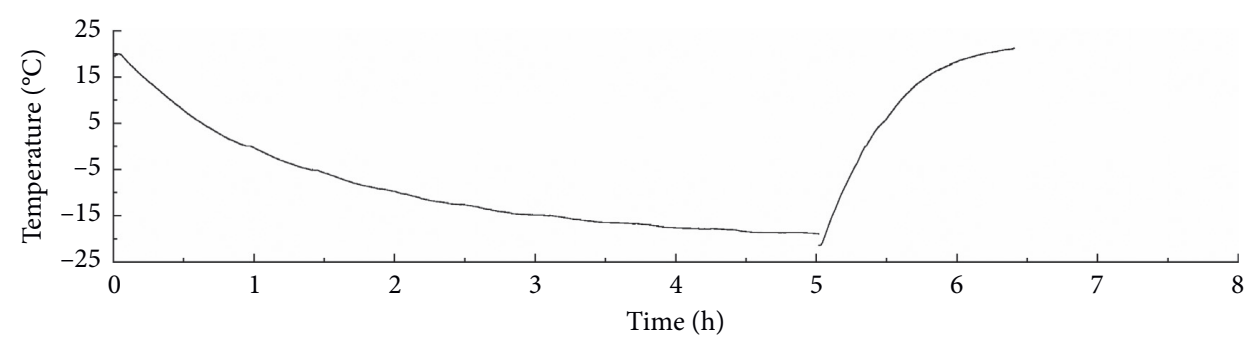

(e)

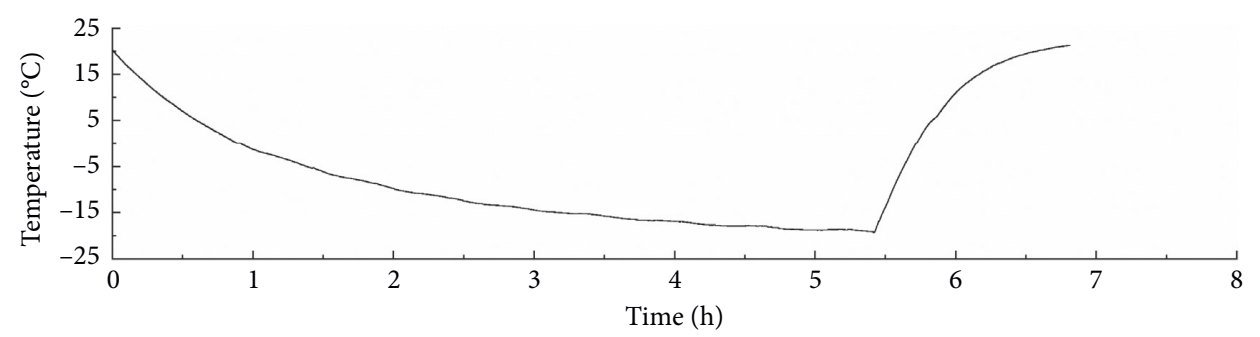

(f)

Figure 3: Continued. 


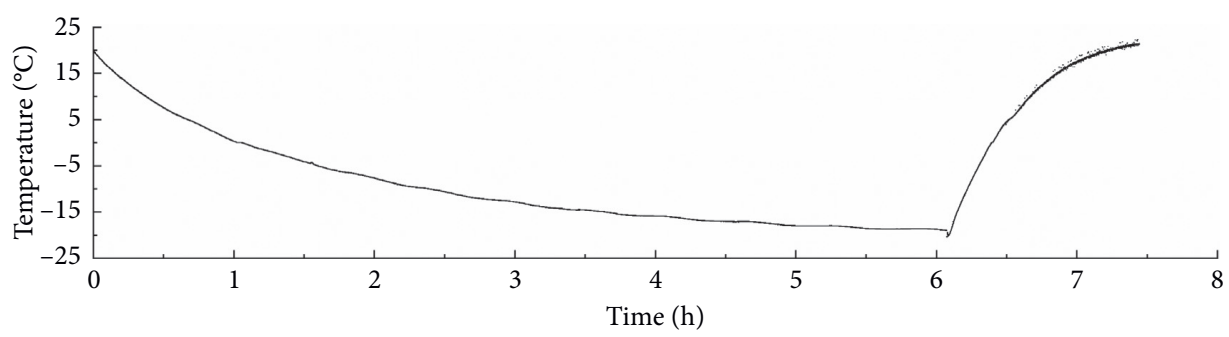

(g)

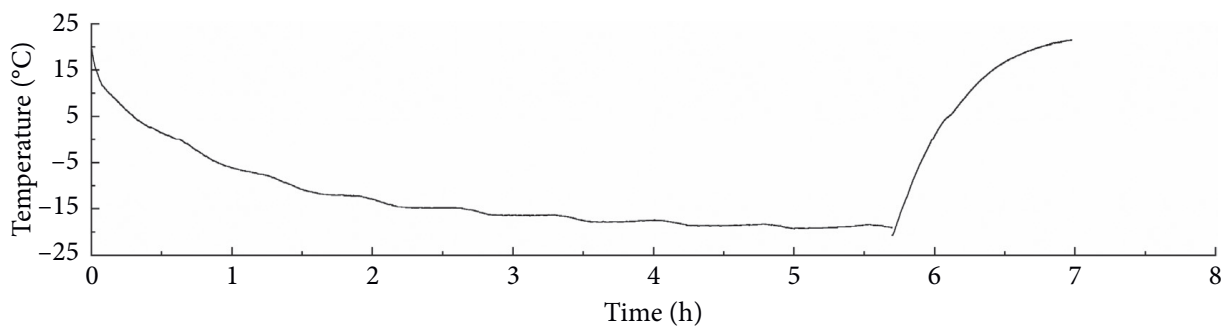

(h)

FiguRe 3: Variation of the internal temperature of the rock sample under different freezing and thawing cycles. (a) $n=5$; (b) $n=10$; (c) $n=15$; (d) $n=20$; (e) $n=25$; (f) $n=30$; (g) $n=35$; (h) $n=40$.

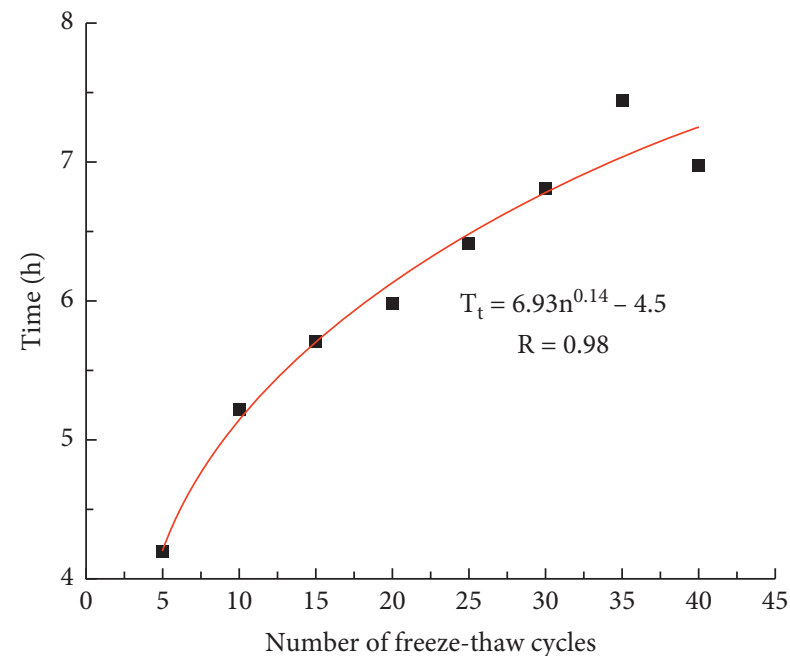

FIGURE 4: Time required for a complete freeze-thaw cycle as a function of freeze-thaw cycles.

$$
\varepsilon=\frac{\left|T_{n+5}-T_{n}\right|}{T_{n}},
$$

where $T_{n}$ and $T_{n+5}$ are the duration of the freezing process when the number of freeze-thaw cycles is $n$ and $n+5$, respectively.

It is found that with the increase of the number of freezethaw cycles, the change rate of the required duration of the thawing process is less than $10 \%$, and the change duration is less than 10 minutes (Figure 7). Each melting process also has three stages: initial melting, ice-water phase transition, and deep melting. The time required for the melting process at different times is plotted in Figure 8. The original data indicate that the thawing phase ranges from $1.1 \mathrm{~h}$ to $1.5 \mathrm{~h}$.
The time taken by this process in the total freeze-thaw duration varies from $25 \%$ in the initial to $17 \%$. The scatter plot shows that the time required to complete the melting process is similar to that of the freezing process. Both processes conform to the law of power functions. Therefore, the power function is also used to obtain the time required for the tuff melting process. The formula for increasing the time required is as follows:

$$
T_{r}=107.5 n^{0.0014}-106.6 \text {, }
$$

where $n$ is the number of freeze-thaw cycles and $T_{r}$ is the time required for the tuff to melt under $n$ times.

3.3. Analysis of Various Stages of the Freezing and Melting Processes. The entire freezing process shows an increasing trend with the number of freezing and thawing cycles. The freezing process is divided into three stages, namely, initial freezing, water-ice phase transition, and deep freezing. The analyses of the test results are shown in Figures 9-11. The test results demonstrate that these three stages also have such properties. The time required for the initial freezing stage is from $0.55 \mathrm{~h}$ in the fifth initial freezing stage to $1 \mathrm{~h}$ in the 40 th initial freezing stage with the increase in the number of freezing and thawing cycles. The water-ice phase transition period is from $114 \mathrm{~s}$ to $135 \mathrm{~s}$, and the deep freezing phase is from $2.6 \mathrm{~h}$ to $5.1 \mathrm{~h}$. The time required for each stage shows an increasing trend with the increase in the number of cycles. However, the calculation and analysis of the experimental results demonstrate that the proportion of the time required for each stage for the time required for the freezing process has not significantly changed with the increase in time. The proportion of time required for the initial freezing stage is approximately $17.9 \%$. The proportions of time required for the water-ice transition and deep freezing phases are approximately $1 \%$ and $82 \%$, respectively. In summary, the 


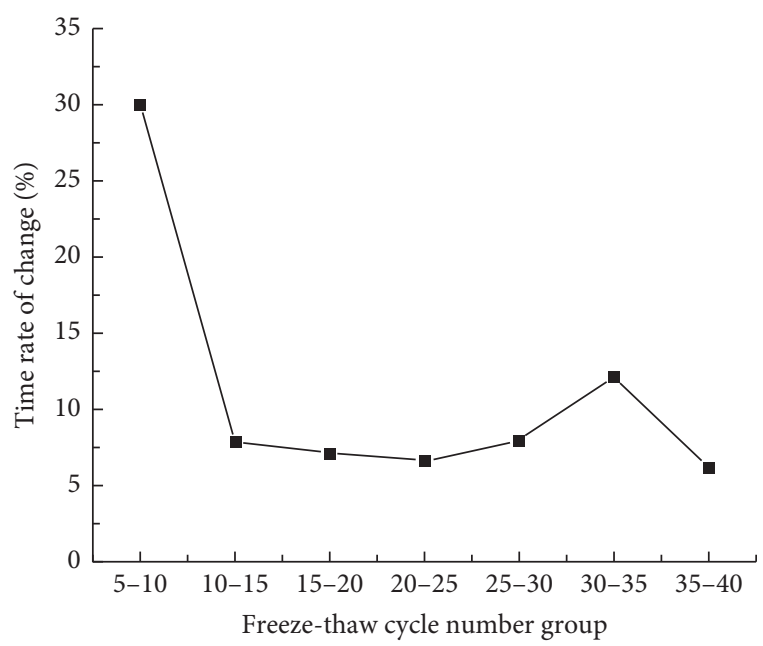

FIgURE 5: The change rate of the duration of the freezing process after every 5 freeze-thaw cycles.

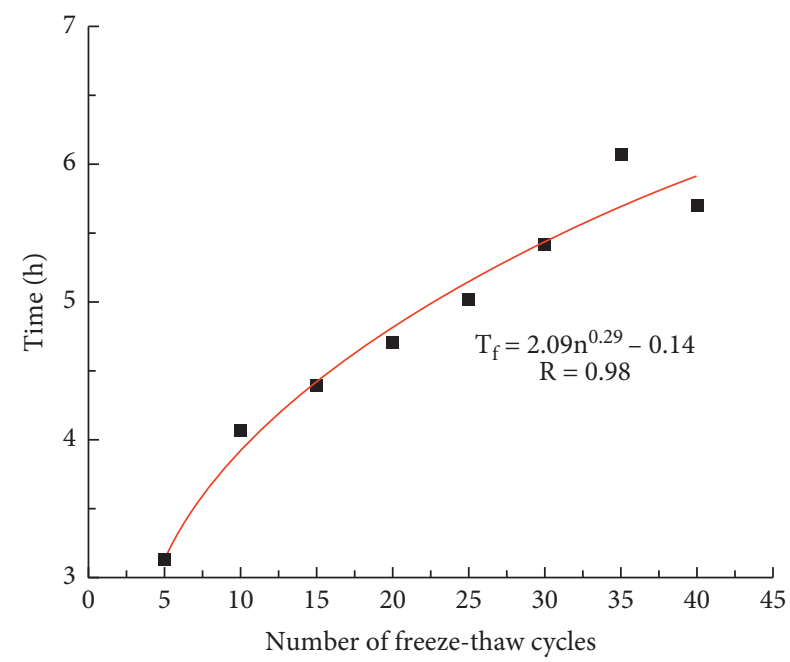

Figure 6: Time required for the freeze process as a function of freeze-thaw cycles.

samples are subjected to freeze-thaw cycles under the condition of no initial replenishment at the later stage of initial saturation. The proportion of the samples in the various stages of the freezing process insignificantly changes with the number of freeze-thaw cycles. The main time distribution is deep freezing stage.

The overall thawing process also shows an increasing trend with the number of freeze-thaw cycles. However, the change and proportion of the total time in the thawing process are smaller than those in the freezing process. Figures 12-14 show the time chart of the three stages in the melting process. Figure 12 demonstrates that the time required for the initial thawing phase is similar to that for the initial freezing phase. The initial heat exchange rate caused by a large internal and external temperature difference is huge. The internal and external temperature difference gradually decreases with the increase in time. The temperature change rate also gradually decreases and eventually stabilizes. This phase accounts for the

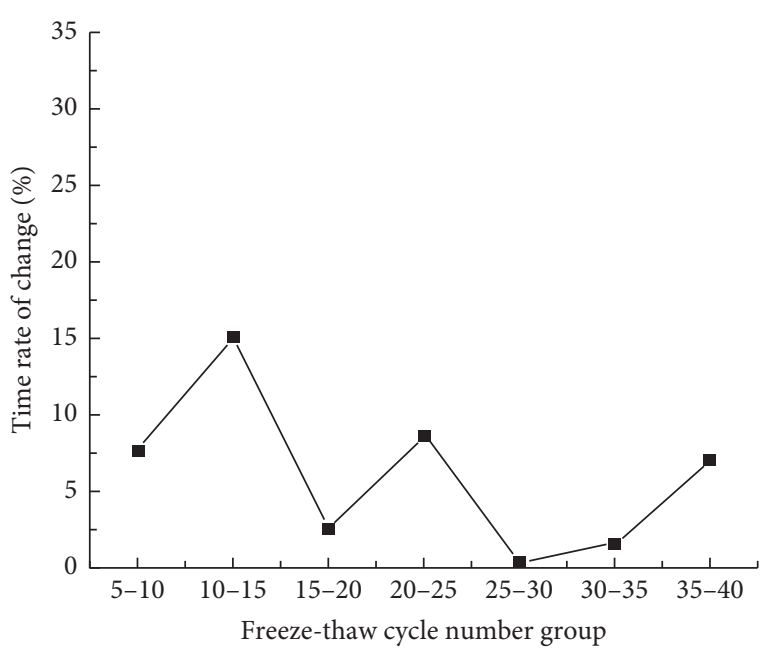

FIGURE 7: The change rate of the duration of the melting process after every 5 freeze-thaw cycles.

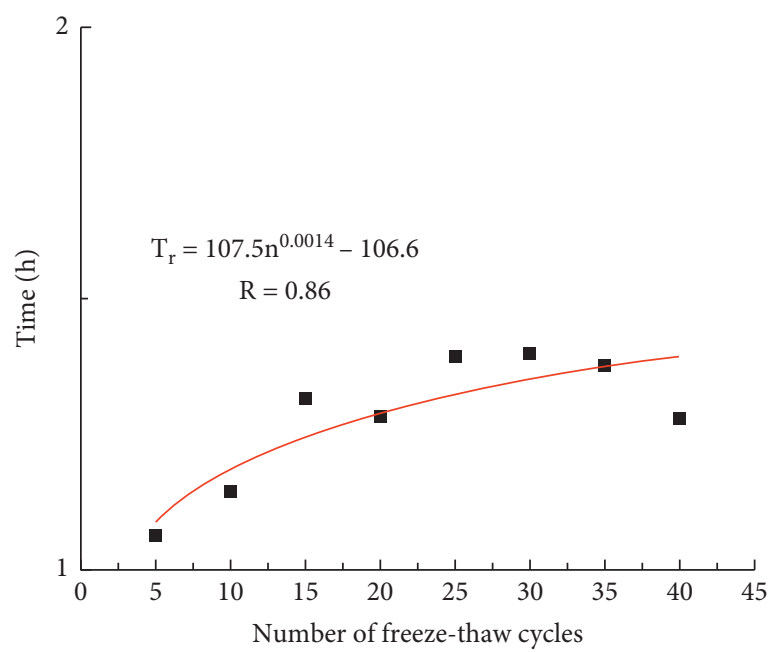

FIGURE 8: Variations in the time required for the melting process as a function of the number of freeze-thaw cycles.

proportion of time in the melting phase from $26 \%$ to $24 \%$. The ice-water phase transition phase is different from the previous one. The time required for the ice-water phase transition phase is almost the same with the increase in the number of freezethaw cycles. However, the process is only a few seconds because of the phase difference. Nevertheless, a tendency to increase will still occur with the increase in the number of cycles. The deep thawing phase is also similar in the deep freezing phase. The rate of time change gradually decreases with the increase in the number of cycles. The proportion of time in the thawing phase is from $73 \%$ to $77 \%$. In the melting process, the proportion of time in each phase correspondingly changes with the increase in the number of freeze-thaw cycles. The main duration is also in the deep thaw phase of the melting process.

\section{Discussion}

Freeze-thaw damage of rock has always been the key content of frost heavy rock research. Many factors affect the degree 


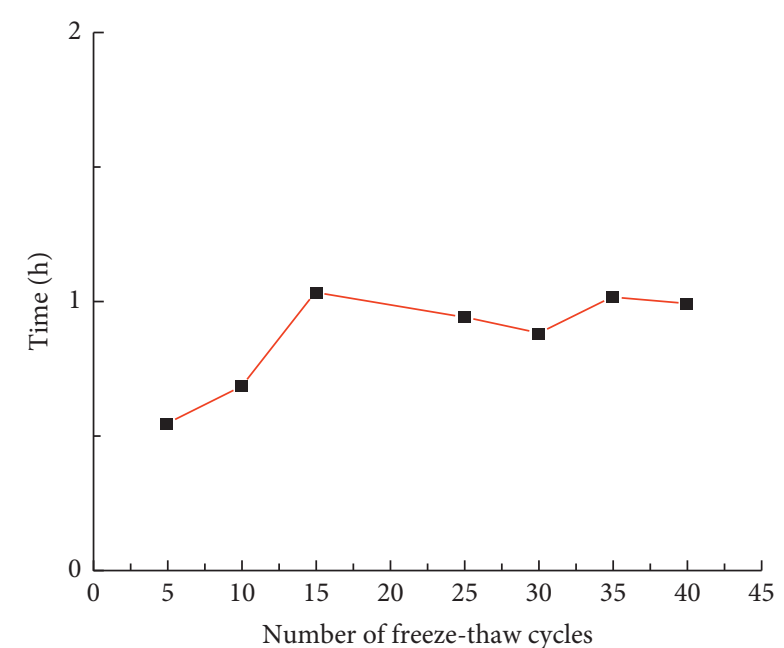

FIgURE 9: Time required for the initial freezing phase as a function of the number of freeze-thaw cycles.

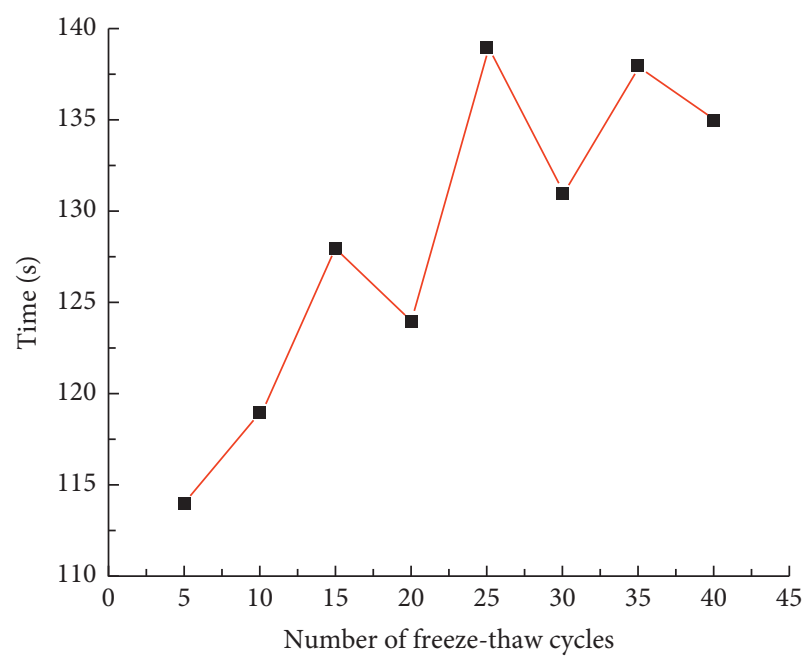

FIGURE 10: Variations in the time required for the water-ice phase change with the number of freeze-thaw cycles.

of freeze-thaw damage. These factors include the temperature range of freeze-thaw cycles, the length of freezethaw cycles, moisture content, lithology, and porosity. Most scholars perform freeze-thaw cycle tests according to the temperature range required by engineering or that of experimental specifications $\left(20^{\circ} \mathrm{C}\right.$ to $\left.-20^{\circ} \mathrm{C}\right)$ for the temperature range of freeze-thaw cycles. Both approaches take one of three durations: $4 \mathrm{~h}$ of freezing and $4 \mathrm{~h}$ of melting, $15 \mathrm{~h}$ of freezing and $9 \mathrm{~h}$ of melting, and $12 \mathrm{~h}$ of freezing and $12 \mathrm{~h}$ of melting. These durations are almost the temperatures in the test specifications. However, the duration's ability to reach the conditions of complete freeze-thaw cycles under different rock and temperature ranges is still unknown. Consequently, the strength of the rock measured in this case may exist to a certain extent. This work combines the standards in the study of rock freeze-thaw damage and uses the standard temperature range $\left(-20^{\circ} \mathrm{C}\right.$ to $20^{\circ} \mathrm{C}$ ) as the test temperature range. Moreover, this work

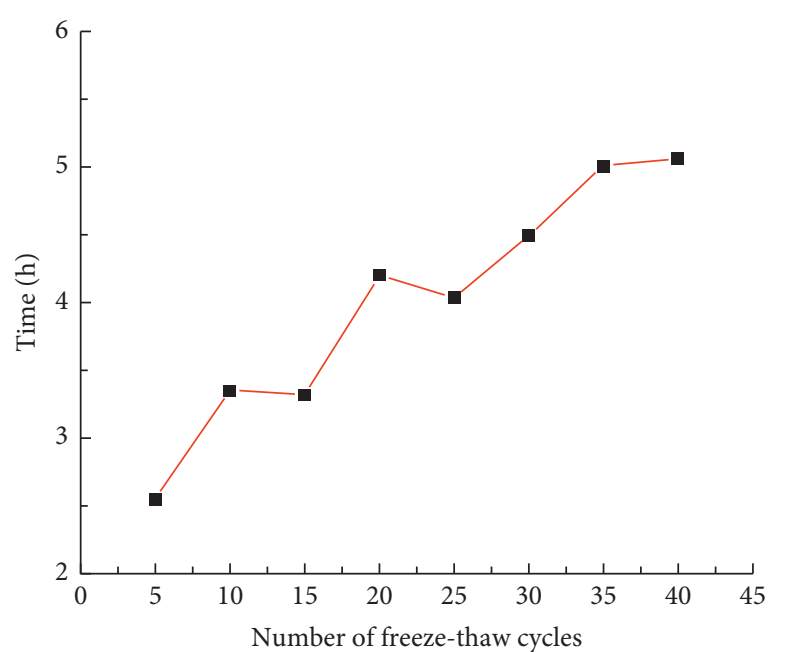

FIgURE 11: Time required for the deep freeze phase as a function of freeze-thaw cycles.

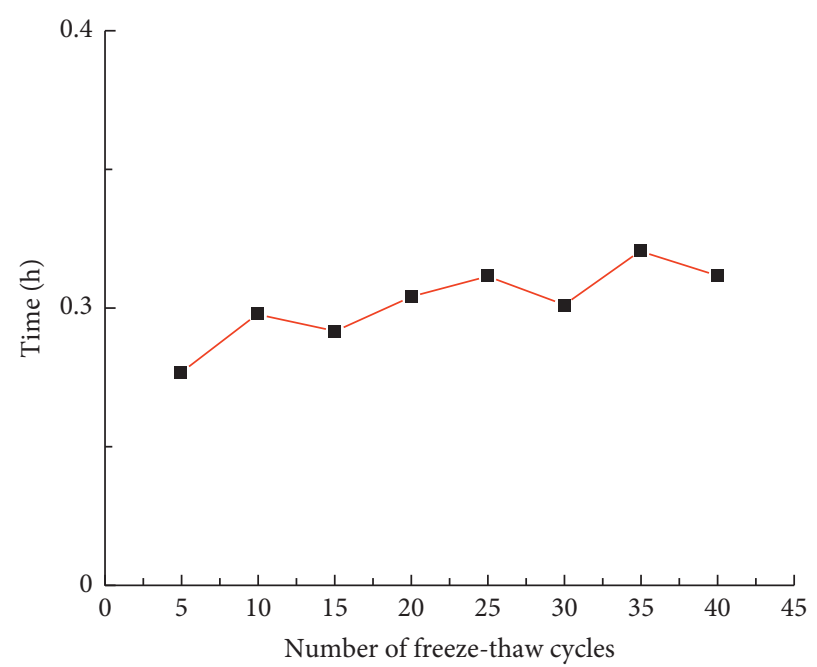

FIGURE 12: Time required for the initial melting phase as a function of freeze-thaw cycles.

measures the time required for a complete freeze-thaw cycle in this range. Table 2 shows the fitting curve of the specific results.

The above changes in the number and duration of freezethaw cycles of tuff demonstrate that the increase in the number of freeze-thaw cycles has a gradual effect on the freeze-thaw cycles of rocks. The overall composition of the rock is composed of the rock mineral body and the internal pores. The internal pores are divided into open pores connected to the external environment and closed pores that are not connected to the outside world. In the first freezing, the rock is in a saturated state. When the temperature gradually decreases, the water gradually begins to undergo water-ice phase transformation, and the volume will expand by $9 \%$. At this time, the frost heave force will be generated in the pore wall. This phenomenon will cause irreversible frost heave damage to the rock, and the fractures in the rock sample will expand and penetrate. The temperature transfer 


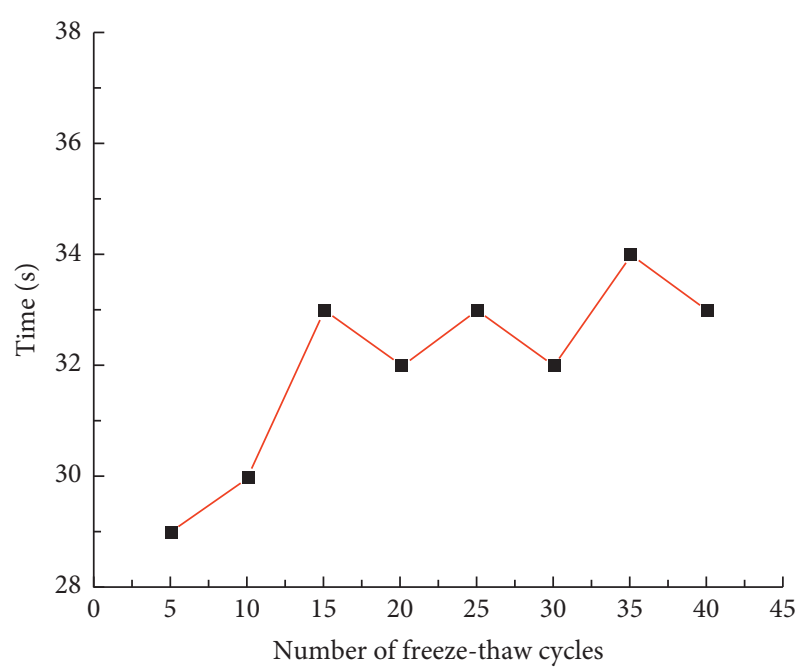

Figure 13: Time required for the ice-water phase transition phase as a function of freeze-thaw cycles.

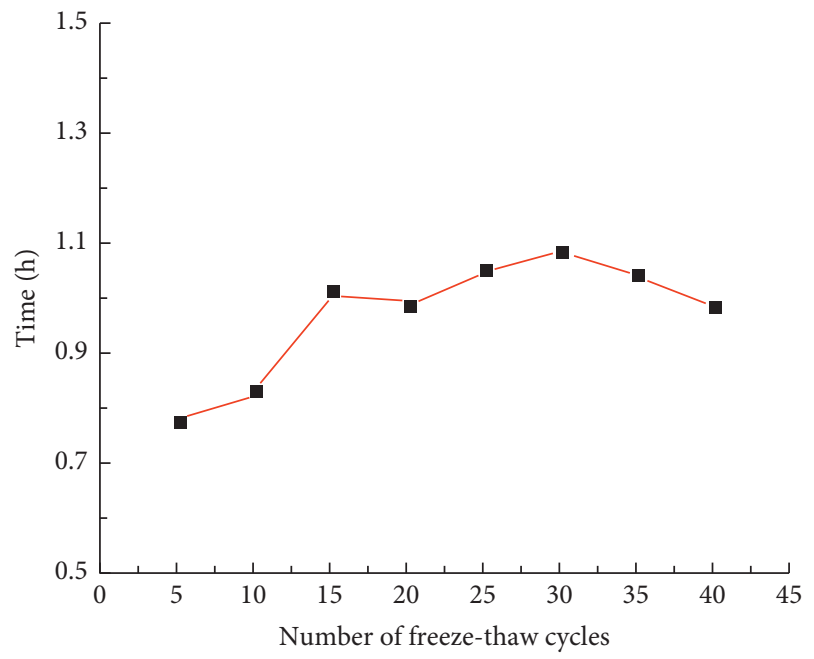

FIgURE 14: Time required for the deep thaw phase as a function of freeze-thaw cycles.

rate in the solid will be greater than the propagation speed in the gas. When the external temperature changes are the same, the internal pores of the rock sample become more and the temperature transfer will become more difficult. Therefore, the time required to reach the complete freezing process will increase as the number of freeze-thaw cycles increases. The degree of crack expansion and penetration is relatively high due to the frost heave effect. Nevertheless, the crack expansion and penetration gradually become difficult with the increase in the number of cycles. This circumstance will result in a gradual smooth change in the temperature transmission and the relative freezing process duration. The duration of the melting process also increases with the expansion and penetration of pores. Nevertheless, the heat required for water to change the temperature is twice than that of ice. Thus, the duration of the melting process is shorter than that of the freezing process.

The experimental data demonstrate that the freeze-thaw time required for 40 times of freeze-thaw cycles of tuff is $8 \mathrm{~h}$.
TABLE 2: Fitting results of the variation of tuff freeze-thaw cycle length with cycle times.

\begin{tabular}{lcc}
\hline & $\begin{array}{c}\text { Freeze-thaw cycle times and freeze- } \\
\text { thaw cycle duration equation }\end{array}$ & $R$ \\
\hline $\begin{array}{l}\text { Freeze-thaw cycle } \\
\text { duration }\end{array}$ & $T_{t}=6.93 n^{0.14}-4.5$ & 0.98 \\
$\begin{array}{l}\text { Freezing process } \\
\text { duration }\end{array}$ & $T_{r}=2.09 n^{0.29}-0.14$ & 0.98 \\
$\begin{array}{l}\text { Duration of the } \\
\text { melting process }\end{array}$ & $T_{f}=107.5 n^{0.0014}-106.6$ & 0.86 \\
\hline
\end{tabular}

However, the freezing process takes $6 \mathrm{~h}$, and the melting process only requires $2 \mathrm{~h}$. The duration of the freezing process of the fifth freeze-thaw cycle is $3 \mathrm{~h}$, thereby meeting the standard duration. However, the duration of the freeze-thaw cycle gradually increases to more than $4 \mathrm{~h}$ with the increase in the number of cycles. The sample will be unable to perform a complete freeze-thaw cycle. Hence, several errors are observed in the various parametric studies. Specifically, the number of freeze-thaw cycles has a certain effect on the duration of the freeze-thaw cycles of tuff. Different cycle lengths also affect the changes in the internal properties of the rock. The change law of rock properties will be further studied.

\section{Conclusion}

The study on the time variation of tuff required to achieve complete freeze-thaw during the freeze-thaw cycle can be concluded on the basis of the freeze-thaw cycle test:

(1) The time required for a complete freeze-thaw cycle of tuff shows a power function increasing trend with the number of freeze-thaw cycles. The trend gradually stabilizes with the increase in the number of times. The freezing and melting processes also show the same law.

(2) The freezing process of tuff is divided into three stages: initial freezing, water-ice phase transformation, and deep freezing. The time required for the three phases increases with the number of freezethaw cycles. However, the proportion of the time required for each phase does not increase with the number of freeze-thaw cycles. The deep freeze phase is the main time proportion of the freezing process.

(3) The tuff melting stage is divided into three stages: initial melting, ice-water phase transformation, and deep melting. The time required for the initial and deep fusion phases increases with time. However, the rate of increase gradually decreases. The proportion of time required gradually decreases with the increase in the number of times in the initial melting stage. The proportion of time in the corresponding deep melting stage gradually increases.

\section{Data Availability}

The data used to support the findings of this study are available from the corresponding author upon request. 


\section{Conflicts of Interest}

The authors declare no conflicts of interest.

\section{Acknowledgments}

The study was funded by the National Natural Science Foundation of China (nos. 41572299 and 41427802), Natural Science Foundation of Zhejiang Province (no. LY18D020003), and Key Research and Development Projects of Zhejiang Province (no. 2019C03104). Their support is gratefully acknowledged.

\section{References}

[1] Y. Zhao, Y. Wang, W. Wang, L. Tang, Q. Liu, and G. Cheng, "Modeling of rheological fracture behavior of rock cracks subjected to hydraulic pressure and far field stresses," Theoretical and Applied Fracture Mechanics, vol. 101, pp. 59-66, 2019.

[2] Y. Zhao, L. Zhang, W. Wang, W. Wen, S. Li, and W. Ma, "Creep behavior of intact and cracked limestone under multilevel loading and unloading cycles," Rock Mechanics \& Rock Engineering, vol. 50, no. 6, pp. 1-16, 2017.

[3] Y. Wang, H. Zhang, H. Lin, Y. Zhao, and Y. Liu, "Fracture behaviour of central-flawed rock plate under uniaxial compression," Theoretical and Applied Fracture Mechanics, vol. 106, Article ID 102503, 2020.

[4] S. Xie, H. Lin, Y. Chen, R. Yong, W. Xiong, and S. Du, "A damage constitutive model for shear behavior of joints based on determination of the yield point," International Journal of Rock Mechanics and Mining Sciences, vol. 128, Article ID 104269, 2020.

[5] H. Lin, D. Lei, and R. Yong, "Analytical and numerical analysis for frost heaving stress distribution within rock joints under freezing and thawing cycles," Environmental Earth Sciences, vol. 79, no. 12, pp. 1-17, 2020.

[6] A. Jamshidi, M. R. Nikudel, and M. Khamehchiyan, "Evaluation of the durability of Gerdoee travertine after freezethaw cycles in fresh water and sodium sulfate solution by decay function models," Engineering Geology, vol. 202, no. 1, pp. 36-43, 2016.

[7] A. Al-Omari, X. Brunetau, B. Kévin, and M. Al-Mukhtar, "Experimental study on the role of freezing-thawing in the degradation of stones in the Castle of Chambord," in International Conference on Built heritage, Monitoring Conservation Management, Milan, Italy, November 2013.

[8] Q. Liu, G. Xu, and X. Liu, "Experimental and theoretical study on freeze-thawing damage propagation of saturated rocks," International Journal of Modern Physics B, vol. 22, no. 09n11, pp. 1853-1858, 2008.

[9] J. Yu, X. Chen, H. Li, J.-W. Zhou, and Y.-Y. Cai, "Effect of freeze-thaw cycles on mechanical properties and permeability of red sandstone under triaxial compression," Journal of Mountain Science, vol. 12, no. 1, pp. 218-231, 2015.

[10] J. Li, R. B. Kaunda, and K. Zhou, "Experimental investigations on the effects of ambient freeze-thaw cycling on dynamic properties and rock pore structure deterioration of sandstone," Cold Regions Science and Technology, vol. 154, pp. 133-141, 2018.

[11] P. Wang, J. Xu, X. Fang, and P. Wang, "Energy dissipation and damage evolution analyses for the dynamic compression failure process of red-sandstone after freeze-thaw cycles," Engineering Geology, vol. 221, pp. 104-113, 2017.

[12] J. Park, C.-U. Hyun, and H.-D. Park, "Changes in microstructure and physical properties of rocks caused by artificial freeze-thaw action," Bulletin of Engineering Geology and the Environment, vol. 74, no. 2, pp. 555-565, 2015.

[13] J. L. Li, K. P. Zhou, W. J. Liu, and Y. Zhang, "Analysis of the effect of freeze-thaw cycles on the degradation of mechanical parameters and slope stability," Bulletin of Engineering Geology and the Environment, vol. 77, no. 2, pp. 573-580, 2018.

[14] A. Momeni, Y. Abdilor, G. R. Khanlari, M. Heidari, and A. A. Sepahi, "The effect of freeze-thaw cycles on physical and mechanical properties of granitoid hard rocks," Bulletin of Engineering Geology and the Environment, vol. 75, no. 4, pp. 1649-1656, 2016.

[15] G. Khanlari, R. Z. Sahamieh, and Y. Abdilor, "The effect of freeze-thaw cycles on physical and mechanical properties of upper red formation sandstones, central part of Iran," Arabian Journal of Geosciences, vol. 8, no. 8, pp. 5991-6001, 2015.

[16] H. Yavuz, R. Altindag, S. Sarac, I. Ugur, and N. Sengun, "Estimating the index properties of deteriorated carbonate rocks due to freeze-thaw and thermal shock weathering," International Journal of Rock Mechanics and Mining Sciences, vol. 43, no. 5, pp. 767-775, 2006.

[17] F. Bayram, "Predicting mechanical strength loss of natural stones after freeze-thaw in cold regions," Cold Regions Science and Technology, vol. 83-84, pp. 98-102, 2012.

[18] N. Matsuoka, "Mechanisms of rock breakdown by frost action: an experimental approach," Cold Regions Science and Technology, vol. 17, no. 3, pp. 253-270, 1990.

[19] S. Demirdag, "Effects of freezing-thawing and thermal shock cycles on physical and mechanical properties of filled and unfilled travertines," Construction and Building Materials, vol. 47, pp. 1395-1401, 2013.

[20] T. Mokhf, P. William, and S. Rafat, "Damage in granite under heating/cooling cycles and water freeze- thaw condition," International Journal of Rock Mechanics and Mining Sciences, vol. 45, no. 7, pp. 1164-1175, 2008.

[21] Y. Huseyin, "Effect of freeze-thaw and thermal shock weathering on the physical and mechanical properties of an andesite stone," Bulletin of Engineering Geology and the Environment, vol. 70, no. 2, pp. 187-192, 2011.

[22] F. Gao, Q. Wang, H. Deng, J. Zhang, W. Tian, and B. Ke, "Coupled effects of chemical environments and freeze-thaw cycles on damage characteristics of red sandstone," Bulletin of Engineering Geology and the Environment, vol. 76, no. 4, pp. 1481-1490, 2017.

[23] The Professional Standards Compilation Group of People Republic of China, SL264-2001 Specifications for Rock Test in Water Conservancy and Hydroelectric Engineering, China Water Power Press, Beijing, China, (in Chinese), 2001.

[24] The Professional Standards Compilation Group of People's Republic of China, JTG E41-2005 Test Methods of Rock for Highway Engineering, China Communication Press, Beijing, China, (in Chinese), 2005.

[25] R. Ulusay, The ISRM Suggested,Methods for Rock Characterization, Testing and Monitoring: 2007-2014, Springer International Publishing, Cham, Switzerland, 2014. 